\title{
BMJ Open Assessing the regional impact of Japan's COVID-19 state of emergency declaration: a population-level observational study using social networking services
}

Daisuke Yoneoka (D) , ,2,3 Shoi Shi, ${ }^{4,5}$ Shuhei Nomura (i) , ${ }^{1,3}$ Yuta Tanoue, ${ }^{6}$ Takayuki Kawashima, ${ }^{7}$ Akifumi Eguchi, ${ }^{8}$ Kentaro Matsuura, ${ }^{9,10}$ Koji Makiyama, ${ }^{10,11}$ Shinya Uryu, ${ }^{12}$ Keisuke Ejima, ${ }^{13}$ Haruka Sakamoto, ${ }^{1,3}$ Toshibumi Taniguchi, ${ }^{14}$ Hiroyuki Kunishima, ${ }^{15}$ Stuart Gilmour, ${ }^{2}$ Hiroshi Nishiura (D) , ${ }^{16}$ Hiroaki Miyata ${ }^{1}$

To cite: Yoneoka D, Shi S, Nomura S, et al. Assessing the regional impact of Japan's COVID-19 state of emergency declaration: a population-level observational study using social networking services. BMJ Open 2021;11:e042002. doi:10.1136/ bmjopen-2020-042002

- Prepublication history and additional material for this paper are available online. To view these files, please visit the journal online (http://dx.doi. org/10.1136/bmjopen-2020042002).

DY, SS, SN, YT, TK and AE contributed equally.

Received 25 June 2020 Revised 02 December 2020 Accepted 29 December 2020

A) Check for updates

(c) Author(s) (or their employer(s)) 2021. Re-use permitted under CC BY-NC. No commercial re-use. See rights and permissions. Published by BMJ.

For numbered affiliations see end of article.

Correspondence to

Dr Hiroaki Miyata; h-m@keio.jp

\section{ABSTRACT}

Objective On 7 April 2020, the Japanese government declared a state of emergency in response to the novel coronavirus outbreak. To estimate the impact of the declaration on regional cities with low numbers of COVID-19 cases, large-scale surveillance to capture the current epidemiological situation of COVID-19 was urgently conducted in this study.

Design Cohort study.

Setting Social networking service (SNS)-based online survey conducted in five prefectures of Japan: Tottori, Kagawa, Shimane, Tokushima and Okayama.

Participants 127121 participants from the five prefectures surveyed between 24 March and 5 May 2020. Interventions An SNS-based healthcare system named COOPERA (COvid-19: Operation for Personalized Empowerment to Render smart prevention And care seeking) was launched. It asks questions regarding postcode, personal information, preventive actions, and current and past symptoms related to COVID-19.

Primary and secondary outcome measures Empirical Bayes estimates of age-sex-standardised incidence rate (EBSIR) of symptoms and the spatial correlation between the number of those who reported having symptoms and the number of COVID-19 cases were examined to identify the geographical distribution of symptoms in the five prefectures.

Results $97.8 \%$ of participants had no subjective symptoms. We identified several geographical clusters of fever with significant spatial correlation $(r=0.67)$ with the number of confirmed COVID-19 cases, especially in the urban centres of prefectural capital cities.

Conclusions Given that there are still several highrisk areas measured by EBSIR, careful discussion on which areas should be reopened at the end of the state of emergency is urgently required using real-time SNS system to monitor the nationwide epidemic.

\section{Strengths and limitations of this study}

- Using data from the social networking service (SNS) messaging application, this study, for the first time, evaluated the impact of Japan's declaration of a state of emergency on regional cities with low numbers of COVID-19 cases.

- This study succeeded in capturing the real-time epidemiology of COVID-19 using SNS data in local Japan and identified several geographical hot spots.

- Caution is necessary as the data were limited to SNS users.

- The results might include recall bias as the data were based on questions asking COVID-19-related symptoms during the past 1 month.

\section{INTRODUCTION}

COVID-19, an infectious disease first reported in Wuhan, Hubei Province, China, has given a lesson in the difficulty of preventing emerging infectious disease epidemics in a global society. ${ }^{1-3}$ About 1 month after the first COVID-19 case report in early January, the first case in Brazil, over $16000 \mathrm{~km}$ away from China, was confirmed, and as of May 11, 215 countries and territories have been confirmed to have been infected, with 4006257 cases and 278892 deaths. ${ }^{45}$

The WHO's declaration of Public Health Emergency of International Concern due to COVID-19 at the end of January triggered many countries to shut down their national borders. However, the virus has spread and domestic countermeasures were urgently implemented, including lockdown of major cities or the whole country. Until 24 March 2020 , around $20 \%$ of the global population were estimated to be in some form of 
lockdown. ${ }^{6}$ The lockdown can surely prevent the spread of virus, but it is difficult to maintain for a long period because there is a trade-off between economics and epidemiology. ${ }^{7}$ US President Trump has issued guidelines for restarting economic activity, but ultimately the decision is reserved for state and municipal leaders. ${ }^{8}$ However, to determine the optimal timing of restarting social and economic activities, the number of infected residents in the whole city, instead of the number of confirmed cases in hospitals, is a necessary information. ${ }^{9}$ To address it, a system to more easily and effectively track positive but unconfirmed cases in real time is urgently needed.

In response to the gradual increase in PCR-positive COVID-19 cases with an untraceable transmission pathway, the Japanese government declared a state of emergency for 7 of the 47 prefectures on the evening of 7 April $^{10}$ and extended it nationwide on 16 April. $^{11}$ This declaration has limited legal force to prohibit people from moving, which distinguishes it from the so-called 'lockdowns'-city blockades with penalties-already in effect in the USA, UK, France, Germany, Italy and India, and thus it is essentially driven by the voluntary efforts of Japanese residents. ${ }^{10}{ }^{11}$ In this sense, Japan has a unique and voluntary-based lockdown policy to weaken the spread of the infection. Since the declaration, in proportion to the decrease in the number of infected people, the importance of the discussion on how to announce the end of the state of emergency and social confinement is increasing. However, even when the number of COVID-19 cases has decreased, since it is affected by the total number of PCR tests and the likelihood of mild cases presenting for testing, it does not mean the epidemic is completely controlled.

Aquestionnaire-based big data analysis can provide information in support of economic reopening, ${ }^{12} 13$ but classic monitoring methods of this kind are time-consuming and logistically challenging. In early April, in collaboration with LINE Corporation, Kanagawa Prefecture launched a novel healthcare support system in Japan, called COOPERA (COvid-19: Operation for Personalized Empowerment to Render smart prevention And care seeking). ${ }^{14}$ LINE provides one of the most famous social network services in Japan, with over 80 million users. Through the LINE app, COOPERA provides users a questionnaire that collects information on demographics, preventive actions, and medical and physical conditions. In response to the provided information, COOPERA provides personalised support, such as telephone consultations for respondents who report serious symptoms. COOPERA is proven to be useful in capturing the COVID-19 epidemic situation ${ }^{15-18}$ and hence may provide important information on the estimate of the risk of re-emergence of infection in real time as well as decisions on reopening local economic activities.

This study is a secondary data analysis from COOPERA and analysed data on five regional areas in Japan between 24 March and 5 May 2020. This study aims (1) to estimate the consistency of the number of participants with non-specific symptoms (fever and strong feeling of weariness or shortness of breath) with the PCR testing in the five prefectures; and (2) to identify potential risk areas by analysing the number of participants with non-specific symptoms and (3) to assess any change before and after the state of emergency. This social networking service (SNS)-based epidemiological analysis would provide pertinent information to control the COVID-19 epidemic in real time, which requires rapid decision making.

\section{METHODS}

\section{Data sources and participants}

COOPERA uses a chatbot that asks participants to report individual information, including their medical conditions (non-specific symptoms, such as fever and fatigue) as well as personal characteristics (see the Outcomes of interest section). The details of COOPERA can be found in Yoneoka et al. ${ }^{18}$ COOPERA recruits participants via the LINE app using a $\mathrm{QR}$ (quick response) code page in the prefecture's website. We obtained data on 127964 participants who live in Tottori, Kagawa, Shimane, Tokushima and Okayama prefectures in Japan (figure 1) from 24, 26, 27, 30 and 31 March to 5 May 2020, respectively. In this study, those who were 15 years of age and older were included. For those who used the COOPERA multiple times, only the first answer was used in the analysis. The five prefectures consist of relatively small and local cities with populations of 0.56 (47th among 47 prefectures), 0.96 (39th), 0.73 (44th), 0.67 (46th) and 1.89 (20th) million, respectively, as of April 2020 (ie, 2.7\% of the total population is covered in this study). In addition to the COOPERA data, we extracted the number of PCR-confirmed COVID-19 cases from each prefecture's web page.

\section{Outcomes of interest}

COOPERA collects personal information regarding (1) demographic characteristics, including age, gender, occupation and postcode; (2) medical information, including medical history and preventive actions for COVID-19; and (3) health conditions, including onset dates of current and past 1 month symptoms related to COVID-19 (ie, fever, strong feeling of weariness or shortness of breath) and the duration of these symptoms. For those who report any symptoms, COOPERA further asks about medical visits and clinical diagnoses, as well as psychological conditions, ${ }^{15}$ which are out of focus of this study. In this study, symptoms are divided into four subgroups: fever above $37.5^{\circ} \mathrm{C}$ (condition A), strong feeling of weariness or shortness of breath (condition $\mathrm{B}$ ), both conditions A and B (condition $\mathrm{C}$ ), or either condition A or B (condition D).

\section{Statistical and geographical analysis}

Basic characteristics were reported with mean, SD or prevalence. The daily prevalence of conditions A-D was calculated throughout the study period as follows: since 


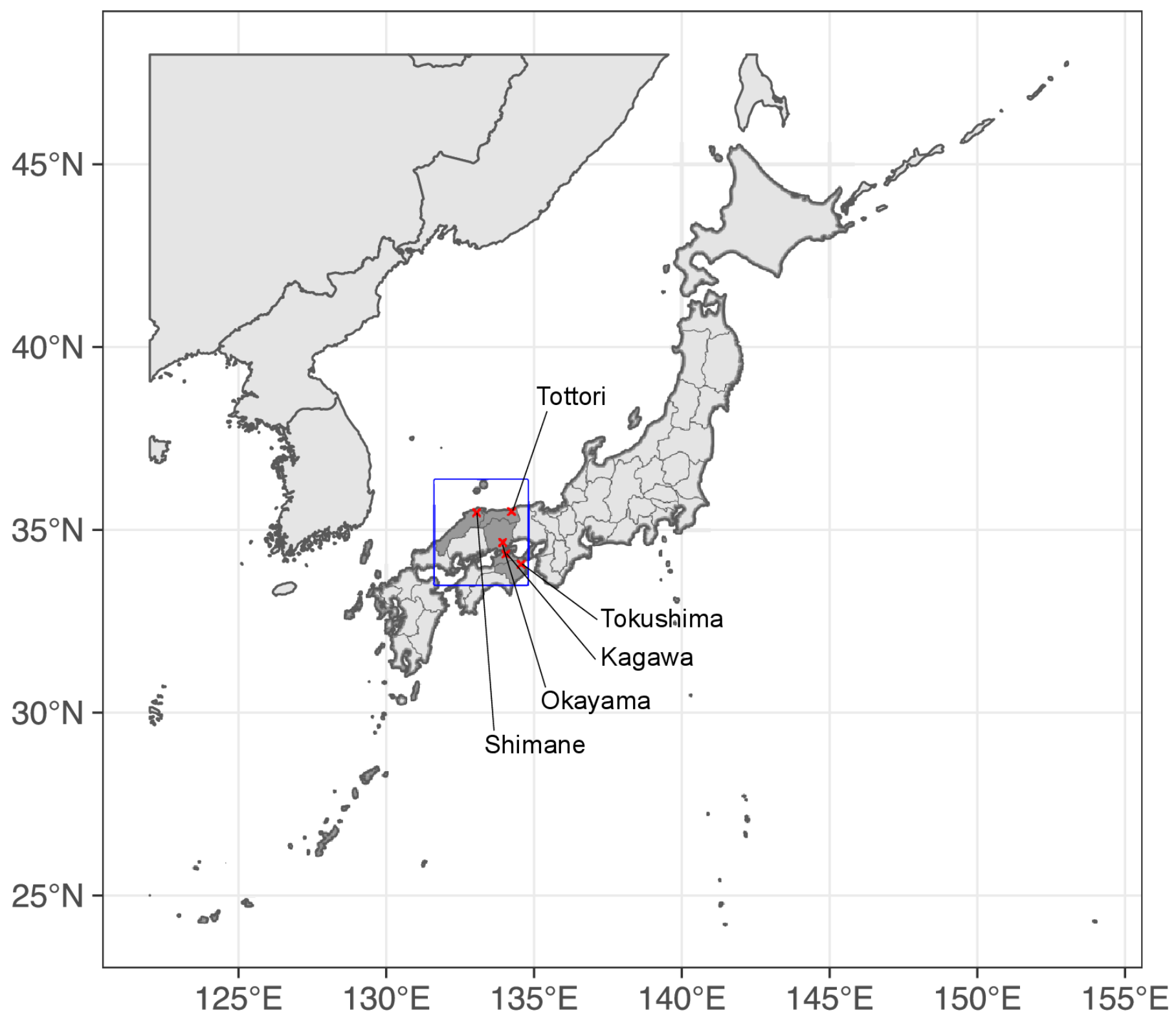

Figure 1 Map of five prefectures: Tottori, Kagawa, Shimane, Tokushima and Okayama.

COOPERA asks for the presence of COVID-19-related symptoms over the past months, for example, if on 20 March a person responds 'fever above $37.5^{\circ} \mathrm{C}$ ' as the current symptom, that person is counted in both the denominator and the numerator of the prevalence on 20 March. Also, in terms of the past 1 month symptoms, if the person had a 'fever above $37.5^{\circ} \mathrm{C}$ ' on 14 March, the answer is also counted in both the denominator and the numerator of the prevalence on 14 March. Note that due to the definition, the more recent the date, the smaller the denominator, resulting in greater likelihood of unstable estimates (see the Discussion section for more details). Therefore, the period for plotting results was restricted to the end of April instead of the end of the study period.

According to the Ministry of Land, Infrastructure, Transport and Tourism in Japan, there were 109 municipalities and 7094 postcodes in the study area at the time of the study. We conducted geographical analysis at both municipality and postcode levels. Latitude and longitude were extracted from map polygon data for each municipality. Empirical Bayes estimates of the age-sexstandardised incidence rate (EBSIR), which are assumed to be independent and identically distributed and follow a gamma prior distribution, were calculated to illustrate the geographical distribution of conditions A-D during the study period. The EBSIR can incorporate the spatial neighbourhood information to smooth the estimate towards the local mean to stabilise the estimation. ${ }^{1920}$ The spatial neighbourhood and its associated local adjacency matrix were defined based on the queen contiguity, where spatial neighbours shared at least a common border. ${ }^{20}$ As a sensitivity analysis for the results by the change of the definition of neighbourhood, we changed the local adjacency matrix based on the $k$-nearest neighbourhood method with $k=10$ and $k=30$ in the online supplemental figure 1 . To examine the geographical distribution in 
more detailed resolution, postcode-level data were used with the $k$-nearest neighbourhood method with $k=60$. To test spatial correlation, $r$, between the number of those who reported having each symptom and the number of confirmed COVID-19 cases, the modified statistical test for spatial correlation coefficient developed by Clifford et $a l^{21}$ was used. The test statistics are calculated based on modified variance and $\mathrm{df}$ of the standard t-test. To examine the impact of the state of emergency in the local area in Japan, the geographical distributions of EBSIR for condition A before and after the declaration were plotted. In addition, to compare the spread of condition A before and after the declaration in detail in Kagawa Prefecture, the smallest prefecture in Japan, we estimated the spatial Gini coefficient, which quantifies the spatial inequality of the risk of condition A among non-neighbours, using a Monte Carlo simulation with 2000 iterations. ${ }^{22}$ A bi-squared weighting scheme and the $k$-nearest neighbourhood method with $k=60$ were assumed for the calculation. Lastly, the mean and SD of EBSIR at each distance from the Kagawa prefectural office (latitude=134.044, longitude $=34.340$ ), which is located at the centre and the most populous area in Kagawa Prefecture, were calculated. Statistical analyses were conducted with R (V.3.6.0) software. The type I error rate was fixed at 0.0125 after Bonferroni correction for multiple testing.

\section{Patient and public involvement}

Patients and the public were not involved in this study as secondary data were the main source.

\section{RESULTS}

A total of 127121 participants were reported, drawn unevenly from Tottori (20659 participants, 16.3\%), Kagawa (21 383, 16.8\%), Shimane (31 498, 24.8\%), Tokushima (10 945, 8.6\%) and Okayama (42 636, 33.5\%) prefectures during 24 March and 5 May 2020. The demographic characteristics of the participants at the initial response date are shown in table 1 by condition type. Of the participants $97.80 \%$ did not have any symptoms (ie, no-symptom group) during the study period, while $0.90 \%, 1.69 \%, 0.38 \%$ and $2.20 \%$ reported conditions $\mathrm{A}, \mathrm{B}, \mathrm{C}$ and $\mathrm{D}$, respectively. The mean and SD of age at the initial question was 43.04 (SD: 12.73). There were more women $(63.2 \%)$ than men $(36.8 \%)$. About $40 \%$ were office workers, followed by part-time workers and unemployed persons at about $11 \%-14 \%$, depending on the conditions. The implementation rate of preventive actions was highest among those without symptoms for all actions, except for 'Take time off from school or work when you have a fever or other symptoms', 'gargling with iodine' and 'Other preventive measure'. Participants with diabetes mellitus were more likely to report symptoms $(4.01 \%, 5.64 \%, 7.36 \%$ and $4.68 \%$ for conditions A, B, $\mathrm{C}$ and D, respectively) than those with other diseases or pregnant people.
Figure 2 shows the geographical distribution of the number of participants with each condition in the five prefectures during the study period, plotted at the municipality level. Within the green box, three subregions in Kagawa Prefecture are plotted in detail at the postcode level. The black lines represent roads. The number of participants with conditions was relatively clustered in prefectural capitals such as Takamatsu and Okayama cities. There was a statistically significant spatial correlation with the number of those who reported having each symptom in figure 3: $r=0.664(\mathrm{p}<0.001), r=0.666$ $(p<0.001), r=0.622(p<0.001)$ and $r=0.665(p<0.001)$ for conditions A, B, C and D, respectively.

Figure 3 shows the estimated EBSIR for each condition at the municipality level. Our estimates suggest that the risk of each condition varies by region within the prefecture. The green box also shows the three regions in Kagawa Prefecture in detail at the postcode level. As a sensitivity analysis, the results of conditions $\mathrm{A}$ and $\mathrm{C}$ using $k=10$ and $k=30$ are presented in online supplemental figure 1. Online supplemental figure 2 illustrates the geographical distribution of PCR-confirmed COVID-19 cases by municipality until 5 May 2020 .

Figure 4 (top and middle) shows the geographical distribution of EBSIR at the postcode level for condition A before (top) and after (middle) the declaration of the state of emergency. The colour contrast between the plots before and after the statement was enlarged, suggesting the gap between high-risk (in red colour) and low-risk (in blue colour) areas has been strengthened. In other words, higher risk areas became higher risk, and lower risk areas became lower risk, after the declaration of emergency. The strengthening in contrast is confirmed by the spatial Gini coefficients before and after the declaration: spatial Gini coefficients were $0.168 \quad(p<0.001)$ and $0.570(\mathrm{p}<0.001)$ for before and after the statement, respectively, which implies that the spatial inequality (or associated colour contrast in figure 4) of the EBSIR grew after the declaration. Figure 4 (bottom) shows the mean and SD of EBSIR for condition A at each distance from the Kagawa prefectural office before and after the declaration. It shows that before the declaration, the risk was spread almost uniformly from the centre, but after the declaration the risk increased with distance from the central area up to $23 \mathrm{~km}$ and became stable beyond this threshold.

\section{DISCUSSION}

To monitor epidemiological trends in COVID-19, this study analysed the data of 127121 participants living in local areas of Japan which reported low numbers of COVID-19 cases, using an SNS-based healthcare system COOPERA. Our SNS-based system has a great advantage in its timeliness: with COOPERA, symptoms can be captured immediately, making data collection quicker than local public health centres. In addition, SNS allows easy tracking of the change in symptoms over time, 
Table 1 Demographic characteristics of participants by health conditions during the study period for the five prefectures combined

\section{Total, $\mathrm{N}=127121$}

\begin{tabular}{|c|c|c|c|c|c|}
\hline & $\begin{array}{l}\text { No symptom } \\
(\mathrm{n}=124319 \\
97.80 \%)\end{array}$ & $\begin{array}{l}\text { (A) Fever } \\
\geq 37.5^{\circ} \mathrm{C}(\mathrm{n}=1146 \text {, } \\
0.90 \%)\end{array}$ & $\begin{array}{l}\text { (B) Strong feeling of } \\
\text { weariness or shortness of } \\
\text { breath ( } n=2145,1.69 \%)\end{array}$ & $\begin{array}{l}\text { Both }(A) \text { and }(B) \\
(n=489,0.38 \%)\end{array}$ & $\begin{array}{l}\text { Either }(A) \text { or }(B) \\
(n=2802,2.20 \%)\end{array}$ \\
\hline \multicolumn{6}{|l|}{ Age, years } \\
\hline Mean (SD) & $43.17(12.7)$ & $38.04(14.1)$ & $37.5(12.37)$ & $39.08(15.3)$ & $37.44(12.54)$ \\
\hline $\begin{array}{l}\text { Range (minimum- } \\
\text { maximum) }\end{array}$ & $15-101$ & $15-101$ & $15-101$ & $15-101$ & $15-101$ \\
\hline $13-19$ & 3279 (2.64) & $72(6.28)$ & $104(4.85)$ & $30(6.13)$ & $146(5.21)$ \\
\hline $20-29$ & $14293(11.50)$ & $242(21.12)$ & 486 (22.66) & $104(21.27)$ & $624(22.27)$ \\
\hline $30-39$ & $31287(25.17)$ & $382(33.33)$ & 706 (32.91) & $149(30.47)$ & 939 (33.51) \\
\hline $40-49$ & $37550(30.2)$ & $234(20.42)$ & 513 (23.92) & $103(21.06)$ & 644 (22.98) \\
\hline $50-59$ & 24753 (19.91) & $120(10.47)$ & $231(10.77)$ & $51(10.43)$ & $300(10.71)$ \\
\hline $60-69$ & 10305 (8.29) & $53(4.62)$ & $70(3.26)$ & $26(5.32)$ & $97(3.46)$ \\
\hline $70-79$ & $2557(2.06)$ & $31(2.71)$ & $21(0.98)$ & $14(2.86)$ & $38(1.36)$ \\
\hline $80-89$ & $281(0.23)$ & $12(1.05)$ & $14(0.65)$ & $12(2.45)$ & $13(0.46)$ \\
\hline$\geq 90$ & $14(0.01)$ & Combined $^{*}$ & Combined $^{*}$ & Combined $^{*}$ & Combined ${ }^{*}$ \\
\hline \multicolumn{6}{|l|}{ Sex } \\
\hline Female & 78655 (63.27) & $672(58.64)$ & $1291(60.19)$ & 262 (53.58) & $1701(60.71)$ \\
\hline Male & $45664(36.73)$ & $474(41.36)$ & $854(39.81)$ & 227 (46.42) & 1101 (39.29) \\
\hline Pregnant & 1624 (1.31) & $19(1.66)$ & $46(2.14)$ & $9(1.84)$ & $56(2.00)$ \\
\hline \multicolumn{6}{|l|}{ Occupation } \\
\hline Self-employed & $11810(9.5)$ & $111(9.69)$ & $216(10.07)$ & $52(10.63)$ & $275(9.81)$ \\
\hline Employees & $50897(40.94)$ & $436(38.05)$ & $806(37.58)$ & 169 (34.56) & $1073(38.29)$ \\
\hline Public officials & $12287(9.88)$ & $91(7.94)$ & $162(7.55)$ & $43(8.79)$ & $210(7.49)$ \\
\hline Student & $4967(4.00)$ & $96(8.38)$ & $138(6.43)$ & $39(7.98)$ & $195(6.96)$ \\
\hline Part-time workers & $17362(13.97)$ & $154(13.44)$ & $303(14.13)$ & $48(9.82)$ & $409(14.6)$ \\
\hline Unemployed & $13626(10.96)$ & $133(11.61)$ & $287(13.38)$ & $76(15.54)$ & $344(12.28)$ \\
\hline Others & $13370(10.75)$ & $125(10.91)$ & $233(10.86)$ & $62(12.68)$ & $296(10.56)$ \\
\hline \multicolumn{6}{|c|}{ Taking antifebrile medications (Loxonin, Calonal and so on) } \\
\hline Current & $1628(1.31)$ & $445(38.83)$ & $578(26.95)$ & $219(44.79)$ & $804(28.69)$ \\
\hline Past 1 month & $4820(3.88)$ & $169(14.75)$ & $432(20.14)$ & $90(18.4)$ & $511(18.24)$ \\
\hline \multicolumn{6}{|c|}{ Diseases currently undergoing treatment (multiple answers) } \\
\hline $\begin{array}{l}\text { Malignant tumour with } \\
\text { anticancer drugs }\end{array}$ & $592(0.48)$ & $9(0.79)$ & $12(0.56)$ & $\leq 5(\leq 1.02)$ & $18(0.64)$ \\
\hline $\begin{array}{l}\text { Malignant tumour } \\
\text { without anticancer } \\
\text { drugs }\end{array}$ & $1144(0.92)$ & $14(1.22)$ & $26(1.21)$ & $9(1.84)$ & $31(1.11)$ \\
\hline $\begin{array}{l}\text { Cardiovascular } \\
\text { diseases }\end{array}$ & $2211(1.78)$ & $32(2.79)$ & $75(3.50)$ & $21(4.29)$ & $86(3.07)$ \\
\hline Kidney diseases & $927(0.75)$ & $11(0.96)$ & $30(1.40)$ & $7(1.43)$ & $34(1.21)$ \\
\hline Diabetes mellitus & $4275(3.44)$ & $46(4.01)$ & $121(5.64)$ & $36(7.36)$ & $131(4.68)$ \\
\hline On dialysis treatment & $127(0.10)$ & $5(0.44)$ & $7(0.33)$ & $\leq 5(\leq 1.02)$ & $8(0.29)$ \\
\hline $\begin{array}{l}\text { Chronic obstructive } \\
\text { pulmonary disease }\end{array}$ & $405(0.33)$ & $13(1.13)$ & $43(2.00)$ & $10(2.04)$ & 46 (1.64) \\
\hline $\begin{array}{l}\text { Treatment with } \\
\text { immunosuppressant }\end{array}$ & $1252(1.01)$ & $18(1.57)$ & 47 (2.19) & $12(2.45)$ & $53(1.89)$ \\
\hline
\end{tabular}

Continued 
Table 1 Continued

Total, $\mathrm{N}=127121$

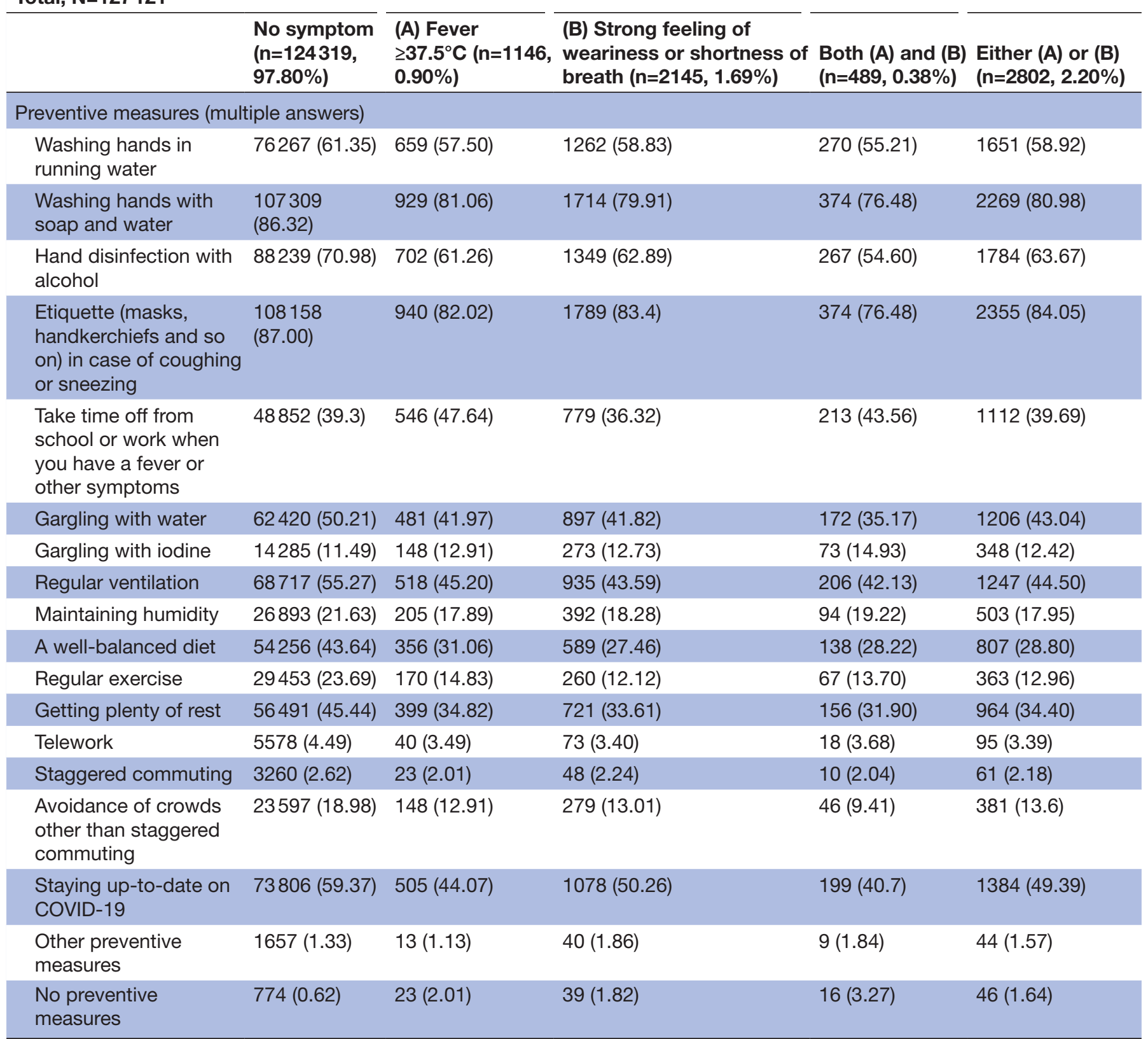

${ }^{*}$ For the purpose of anonymisation, if there was one item with fewer than five people in each variable, it was combined with the numbers in the item above. If there were more than one item with less than five people, each is indicated as 'less than five people'.

such as the date of symptom occurrence, diagnosis and recovery. We found that $0.90 \%(1146)$ of participants had fever (condition A) and $0.38 \%$ (489) had fever and strong feelings of weariness or shortness of breath (condition $\mathrm{C}$ ) during 24 March and 5 May, including the date of the declaration of the state of emergency on 7 April. It should be noted that our outcomes of interest (ie, fever and strong feeling of weariness or shortness of breath) are just surrogate indicators of the COVID-19 infection, implicating that the number of participants with such symptoms might be affected by both COVID-19 and other cases such as cold and influenza A and B. In that sense, our results overestimate the prevalence of COVID-19. However, Sakamoto et $a l^{23}$ reported the seasonal influenza in 2020 in Japan is less active than in previous years, ${ }^{23}$ which suggests that the system has (at least partially) captured the COVID-19 epidemiological situation.

We illustrated the geographical distribution of the estimated EBSIR for non-specific symptoms. We also showed the significant spatial correlation between such symptoms and the number of PCR-confirmed cases of COVID-19 ( $\mathrm{r}=0.62-0.67)$. This implies that COOPERA can partially capture geographical clusters of COVID-19 cases by observing the real-time number of symptoms 

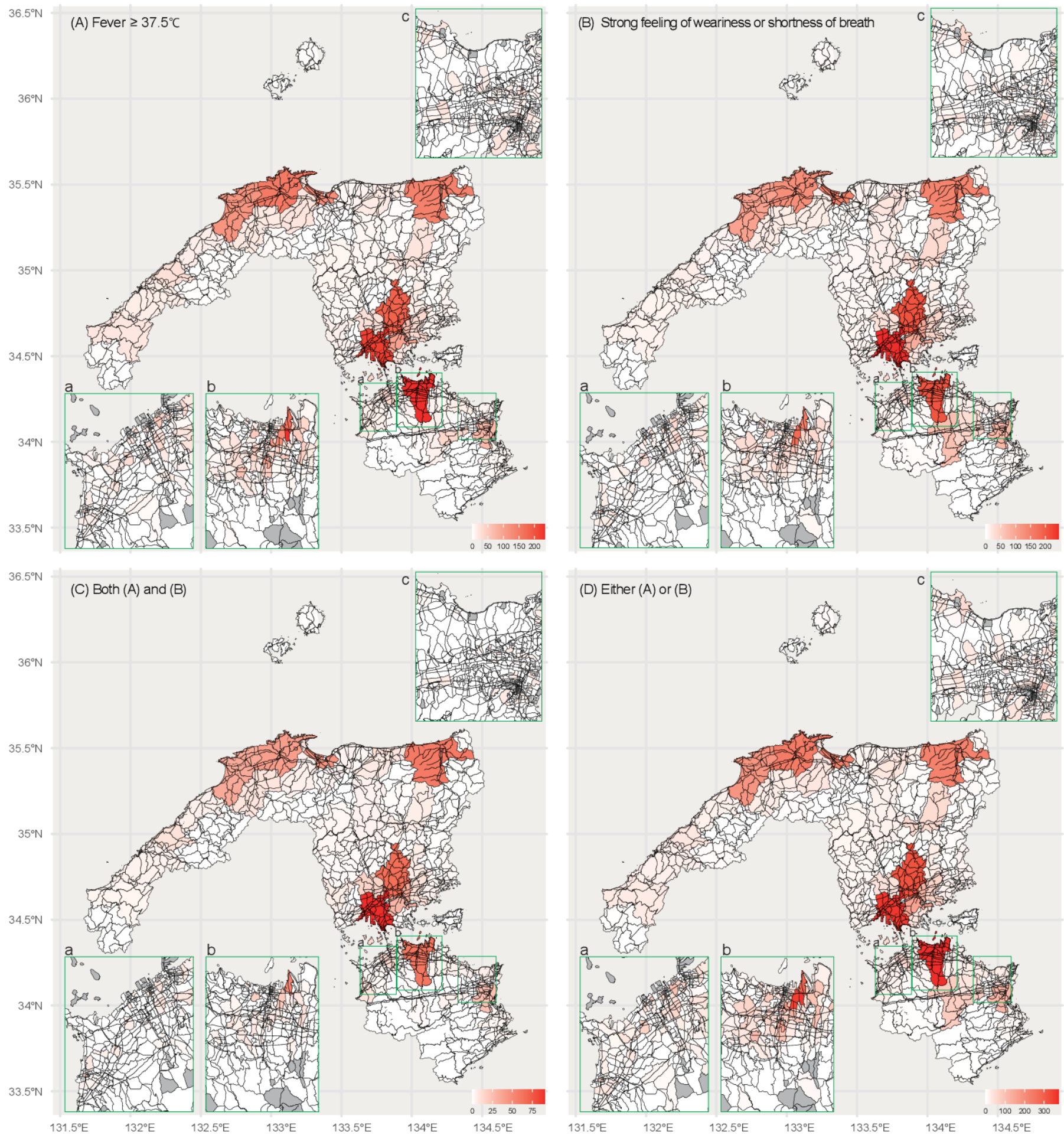

Figure 2 Maps of the number of non-specific symptoms in five prefectures. The black line represents the road network. The blocks are divided by municipality. The thin black line indicates boundaries. Within the green box, three subregions in Kagawa Prefecture are plotted by postcode level. Panels: (A) condition A (fever); (B) condition B (strong feeling of weariness or shortness of breath); (C) both conditions A and B; and (D) either condition A or B. The grey areas indicate there were no participants.

even in the area with low reported numbers of COVID-19 cases. In addition, we found several geographically highrisk areas with high EBSIR, especially in downtown or prefectural capital cities: for example, around Takamatsu, Marugame and Tokushima, cities are likely to form relatively larger geographical clusters of condition A. Further, although additional examination is required, it seems that geographical clusters follow with roads (black line in the figures), especially around road-crossing hubs. Based on this evidence, we can discuss how medical and human resources to combat COVID-19 should be allocated. In terms of the impact of the state of emergency, we observed a clear-cut inflation of Gini coefficients and a colour contrast of the spread of EBSIR between before and after 

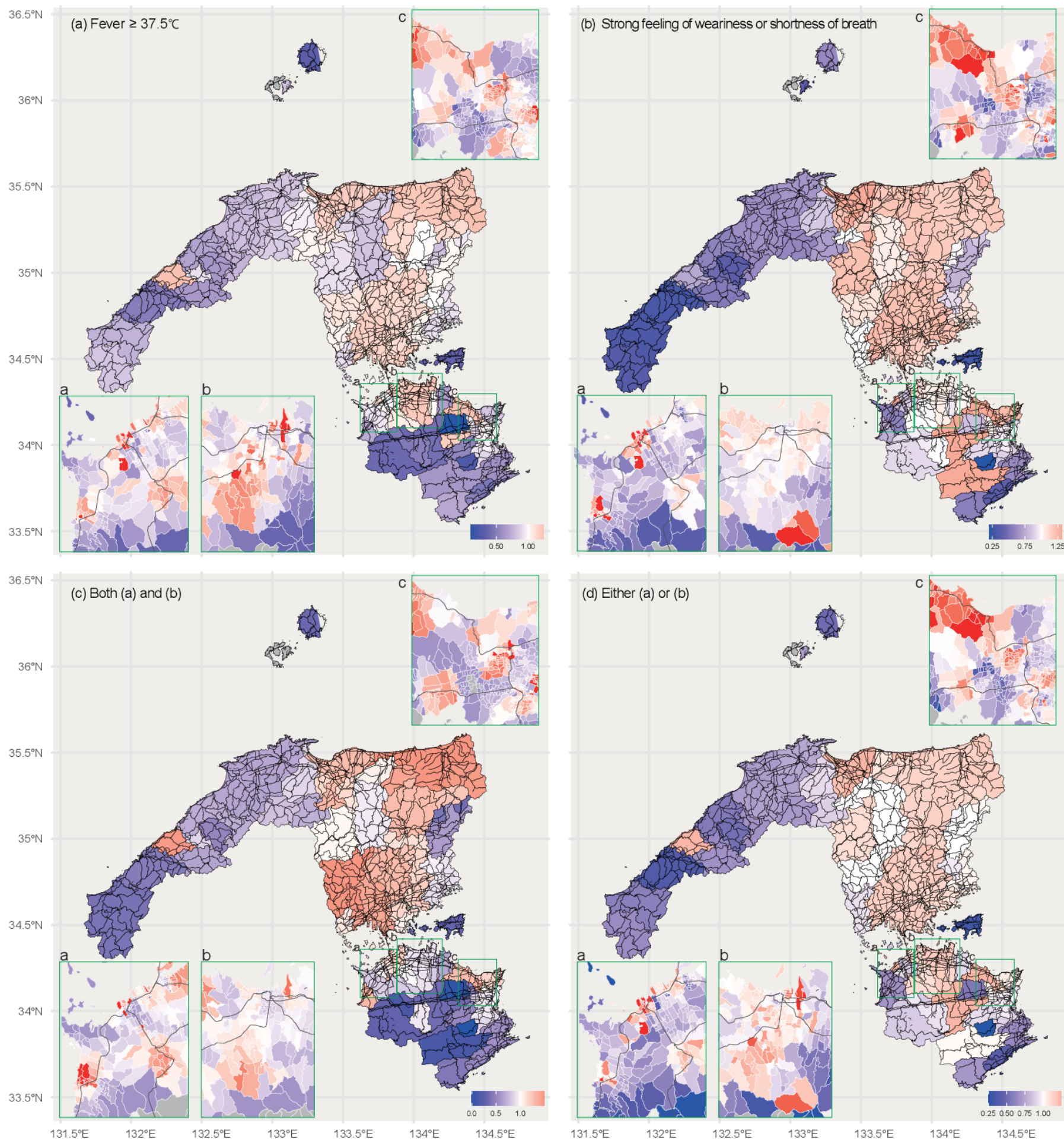

Figure 3 Maps plotting the age-sex-standardised incidence rate of the risk of non-specific symptoms in five prefectures. The black line represents the road network. The blocks are divided by municipality. The white line indicates boundaries. Within the green box, three subregions in Kagawa Prefecture are plotted by postcode level. Panels: (A) condition A (fever); (B) condition B (strong feeling of weariness or shortness of breath); (C) both conditions A and B; and (D) either condition A or B. The grey areas indicate there were no participants.

the declaration. After the statement, it appears that fever cases were locked in certain local areas, preventing the spread of the infection to other neighbourhood areas, indicating that even though the declaration has limited legally enforceable measures, such as prohibiting the movement of residents, the declaration had a lockdown-like effect in the sense that high-risk areas became higher and low risk areas became lower after the declaration.

There are several limitations to this research. The first is bias related to participants' features. Since our monitoring was not a random sampling scheme through the online tool LINE, our results might include sampling bias: those 

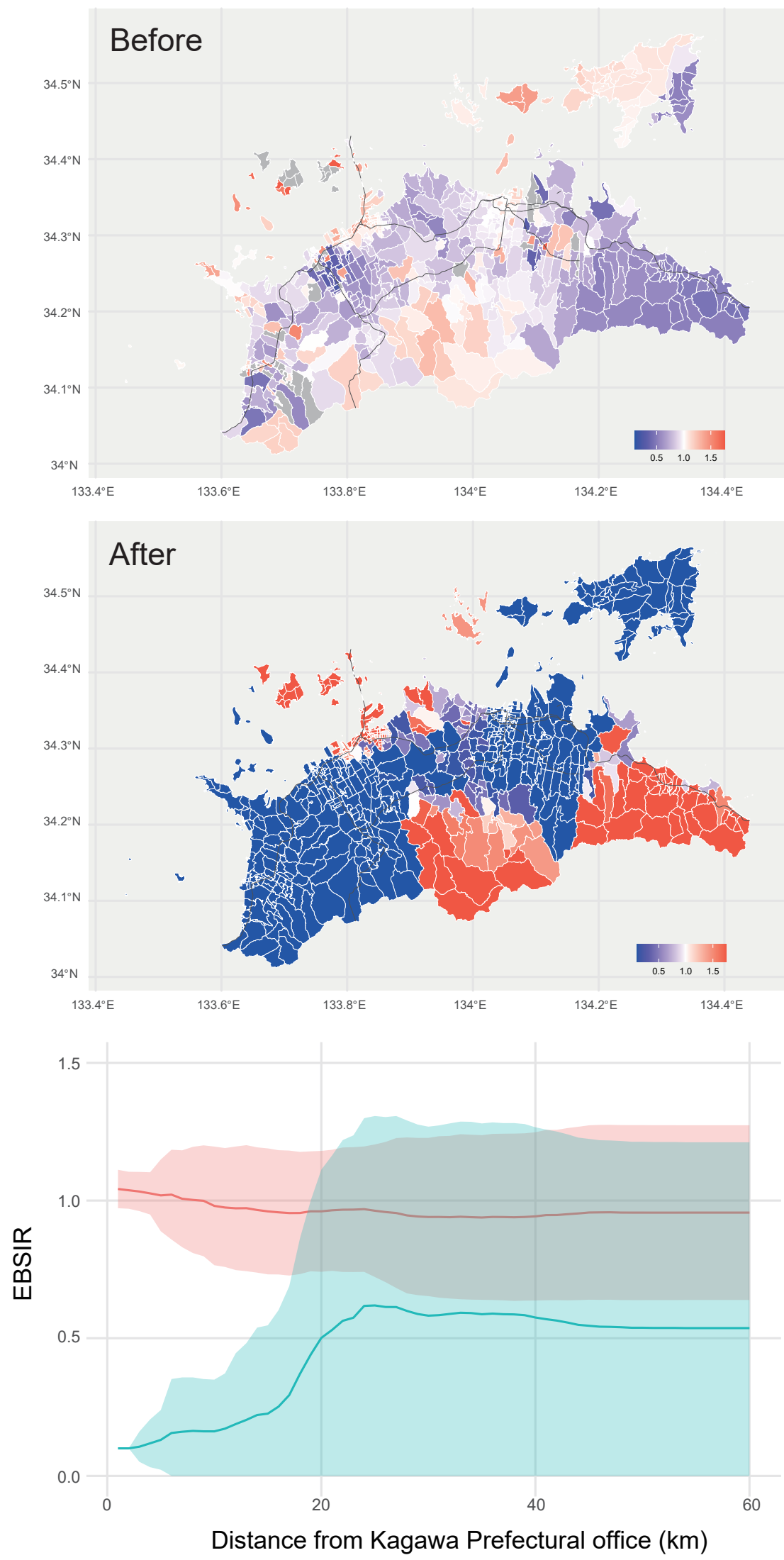

Before

After

Figure 4 Maps plotting the age-sex-standardised incidence rate (EBSIR) of having condition A at the postcode level in Kagawa Prefecture before (top) and after (middle) the declaration of state of emergency, and (bottom) the mean and SD of EBSIR by distance from the Kagawa prefectural office. The grey areas indicate there were no participants. 
who have no access to the internet, smartphone or LINE app may be under-represented. Further, our result might include respondent bias: LINE users who have relatively stronger anxiety from any symptoms or at high-risk environment might have stronger motivation to answer the questionnaire, resulting in overestimation. Unfortunately, no detailed data on user backgrounds such as gender, age and prefecture of residence are available. Therefore, it is difficult to verify the sampling bias. Second, our result might include recall bias: our monitoring contained questions asking symptoms during the past 1 month, and thus the further back in time we account for, the more uncertain the result becomes. Lastly, we should note that the daily changes in the number of the denominator in the prevalence are shown in online supplemental figure 3, showing that the denominator has declined since 1 April and has been particularly low in recent weeks. Therefore, the estimation accuracy might be low in the recent weeks. Other limitations are discussed extensively in Yoneoka $e t$ $a .^{18}$

In summary, this study is the first report using largescale data (over 120000 participants) to monitor the COVID-19 pandemic situation in regional areas in Japan with low reported numbers of COVID-19 cases. Given that there are still several high-risk areas, careful discussion on which area should be reopened first is urgently required, which is the key to control the local and nationwide epidemic in Japan. In addition, given that Japan has a unique and weak lockdown policy to slow down the speed of transmission between cities, our result would also be helpful in preparing for the second or third wave without a strong lockdown to protect the local economy not only in European countries and the USA, but also in developing countries.

\section{Author affiliations}

${ }^{1}$ Department of Health Policy and Management, School of Medicine, Keio University, Tokyo, Japan

${ }^{2}$ Division of Biostatistics and Bioinformatics, Graduate School of Public Health, St Luke's International University, Tokyo, Japan

${ }^{3}$ Department of Global Health Policy, Graduate School of Medicine, The University of Tokyo, Tokyo, Japan

${ }^{4}$ Department of Systems Pharmacology, Graduate School of Medicine, The University of Tokyo, Tokyo, Japan

${ }^{5}$ Laboratory for Synthetic Biology, RIKEN Center for Biosystems Dynamics Research, Osaka, Japan

${ }^{6}$ Institute for Business and Finance, Waseda University, Tokyo, Japan

${ }^{7}$ Department of Mathematical and Computing Science, Tokyo Institute of Technology, Tokyo, Japan

${ }^{8}$ Department of Sustainable Health Science, Center for Preventive Medical Sciences, Chiba University, Chiba, Japan

${ }^{9}$ Department of Management Science, Graduate School of Engineering, Tokyo

University of Science, Tokyo, Japan

${ }^{10} \mathrm{HOXO}$-M, Tokyo, Japan

${ }^{11}$ Yahoo Japan Corporation, Tokyo, Japan

${ }^{12}$ Center for Environmental Biology and Ecosystem Studies, National Institute for Environmental Studies, Japan, Tsukuba, Japan

${ }^{13}$ Department of Epidemiology and Biostatistics, Indiana University School of Public Health-Bloomington, Bloomington, Indiana, USA

${ }^{14}$ Department of Infectious Diseases, Chiba University, Chiba, Japan

${ }^{15}$ Department of Infectious Diseases, St. Marianna University School of Medicine, Kanagawa, Japan
${ }^{16}$ School of Public Health, Kyoto University, Kyoto, Japan

Acknowledgements We would like to thank the officials and residents of Kagawa, Tokushima, Okayama, Tottori and Shimane prefectures for installing the COOPERA system and providing us with data, LINE Corporation for developing and maintaining the system, and Amazon Web Services for providing data storage space. We are also grateful to the Japanese Society of Infectious Diseases for supervising the questionnaires and information provided to the participants from professional perspectives.

Contributors DY, SS, SN, YT, TK and AE conceived and designed the study and take responsibility for the integrity of the data and the accuracy of the data analysis. SN and HM acquired the data. DY, SS, SN, YT, TK and AE conducted statistical analysis and all authors contributed to interpreting the results. DY and SS drafted the article. SG, HN and HM supervised the study and with KeM, KoM, SU, KE, HS, TT and HK critically reviewed the manuscript. All authors gave final approval of the manuscript.

Funding The present work was supported in part by a grant from the Ministry of Health, Labour and Welfare of Japan ('H29-Gantaisaku-ippan-009').

Map disclaimer The depiction of boundaries on this map does not imply the expression of any opinion whatsoever on the part of BMJ (or any member of its group) concerning the legal status of any country, territory, jurisdiction or area or of its authorities. This map is provided without any warranty of any kind, either express or implied.

Competing interests HM reports grant from the Ministry of Health, Labour and Welfare of Japan. KM reports personal fees from Janssen Pharmaceutical Companies of Johnson \& Johnson, outside the submitted work. All other authors declare no competing interests.

\section{Patient consent for publication Not required.}

Ethics approval Ethical approval was granted by the ethics committee of Keio University School of Medicine, under authorisation number 20190338. We used data from only those who gave consent for the prefecture that administers the questionnaire to provide their information to a third party for research use. Respondents are required to give consent before they proceed to the questionnaire response page on the LINE chatbot.

Provenance and peer review Not commissioned; externally peer reviewed.

Data availability statement № additional data are available.

Supplemental material This content has been supplied by the author(s). It has not been vetted by BMJ Publishing Group Limited (BMJ) and may not have been peer-reviewed. Any opinions or recommendations discussed are solely those of the author(s) and are not endorsed by BMJ. BMJ disclaims all liability and responsibility arising from any reliance placed on the content. Where the content includes any translated material, BMJ does not warrant the accuracy and reliability of the translations (including but not limited to local regulations, clinical guidelines, terminology, drug names and drug dosages), and is not responsible for any error and/or omissions arising from translation and adaptation or otherwise.

Open access This is an open access article distributed in accordance with the Creative Commons Attribution Non Commercial (CC BY-NC 4.0) license, which permits others to distribute, remix, adapt, build upon this work non-commercially, and license their derivative works on different terms, provided the original work is properly cited, appropriate credit is given, any changes made indicated, and the use is non-commercial. See: http://creativecommons.org/licenses/by-nc/4.0/.

\section{ORCID iDs}

Daisuke Yoneoka http://orcid.org/0000-0002-3525-5092

Shuhei Nomura http://orcid.org/0000-0002-2963-7297

Hiroshi Nishiura http://orcid.org/0000-0003-0941-8537

\section{REFERENCES}

1 Li Q, Guan X, Wu P, et al. Early transmission dynamics in Wuhan, China, of novel coronavirus-infected pneumonia. N Engl J Med 2020;382:1199-207.

2 Wu Z, McGoogan JM. Characteristics of and important lessons from the Coronavirus disease 2019 (COVID-19) outbreak in China: summary of a report of 72314 cases from the Chinese center for disease control and prevention. JAMA 2020;323:1239-1242.

3 Wang Y, You XY, Wang YJ, et al. [Estimating the basic reproduction number of COVID-19 in Wuhan, China]. Zhonghua Liu Xing Bing Xue Za Zhi 2020;41): :476-9. 
4 Johns Hopkins Coronavirus Resource Center. Coronavirus COVID-19 global cases by the center for systems science and engineering (CSSE) at Johns Hopkins University (JHU), 2020. Available: https:// coronavirus.jhu.edu/map.htm

5 World Health Organization. Coronavirus disease (COVID-19) pandemic, 2020. Available: https://www.who.int/emergencies/ diseases/novel-coronavirus-2019

6 Guardian T. Around $20 \%$ of global population under coronavirus lockdown, 2020. Available: https://www.theguardian.com/world/ 2020/mar/24/nearly-20-of-global-population-under-coronaviruslockdown

7 Fernandes N. Economic effects of coronavirus outbreak (COVID-19) on the world economy, 2020. Available: https://papers.ssrn.com/ sol3/papers.cfm?abstract_id=3557504

8 JOURNAL TWS. Trump's guidelines to reopen economy put Onus on Governors, 2020. Available: https://www.wsj.com/articles/trump-setto-unveil-guidelines-for-lifting-coronavirus-restrictions-11587050541

9 U.S.News. There aren't enough Coronavirus test kits to safely reopen America, Experts Warn, 2020. Available: https://www.usnews. com/news/health-news/articles/2020-04-27/there-arent-enoughcoronavirus-test-kits-to-safely-reopen-america-experts-warn

10 Cabinet Secretariat. Press conference by the prime minister regarding the declaration of a state of emergency, 2020. Available: https://japan.kantei.go.jp/98_abe/statement/202004/_00001.html

11 Cabinet Secretariat. Declaration of a state of emergency in response to the novel coronavirus disease, 2020. Available: https://japan. kantei.go.jp/ongoingtopics/_00020.html

12 Wang CJ, Ng CY, Brook RH. Response to COVID-19 in Taiwan: big data analytics, new technology, and proactive testing. JAMA 2020;323:1341-1342.
13 lenca $\mathrm{M}$, Vayena $\mathrm{E}$. On the responsible use of digital data to tackle the COVID-19 pandemic. Nat Med 2020;26:463-4.

14 Line Corporation. Line Corporation, 2020. Available: https://linecorp. com/en/

15 Tanoue Y, Nomura S, Yoneoka D, et al. Mental health of family, friends, and co-workers of COVID-19 patients in Japan. Psychiatry Res 2020;291:113067.

16 Yoneoka D, Kawashima T, Tanoue Y, et al. Early SNS-Based monitoring system for the COVID-19 outbreak in Japan: a population-level observational study. J Epidemiol 2020;30:362-70.

17 Yoneoka D, Tanoue Y, Kawashima T, et al. Large-Scale epidemiological monitoring of the COVID-19 epidemic in Tokyo. The Lancet Regional Health - Western Pacific 2020;3:100016.

18 Yoneoka D, Kawashima T, Tanoue Y, et al. Early SNS-Based monitoring system for the COVID-19 outbreak in Japan: a population-level observational study. J Epidemiol 2020;30:362-70

19 Clayton D, Kaldor J. Empirical Bayes estimates of agestandardized relative risks for use in disease mapping. Biometrics 1987;43:671-81.

20 Lawson AB. Bayesian disease mapping: hierarchical modeling in spatial epidemiology. Boca Raton, Florida: CRC Press, 2013.

21 Clifford P, Richardson S, Hémon D. Assessing the significance of the correlation between two spatial processes. Biometrics 1989;45:123-34

22 Rey SJ, Smith RJ. A spatial decomposition of the Gini coefficient. Lett Spat Resour Sci 2013;6:55-70.

23 Sakamoto $\mathrm{H}$, Ishikane $\mathrm{M}$, Ueda P. Seasonal influenza activity during the SARS-CoV-2 outbreak in Japan. JAMA 2020;323:1969. 